UDK: 502.131.1:621.548

DOI: https://doi.org/10.24867/15GI08Mitic

\title{
UNAPREĐENJE SKLADIŠNOG POSLOVANJA U KOMPANIJI CARLSBERG ČELAREVO
}

\section{IMPROVEMENT OF WAREHOUSING BUSINESS IN THE COMPANY CARLSBERG ČELAREVO}

\author{
Lana Mitić, Fakultet tehničkih nauka, Novi Sad
}

\section{Oblast - INŽENJERSKI MENADŽMENT, KVALITET I LOGISTIKA}

Kratak sadržaj - Na primeru organizacije CARLSBERG SRBIJA D.O.O., ČELAREVO, izvršena je analiza procesa skladištenja. Primenom odgovarajućih metoda i tehnika, identifikovani su i analizirani najznačajniji nedostataci $u$ navedenom procesu $i$ na osnovu dobijenih rezultata analize, predložene su mere unapređenja.

Ključne reči: Logistika, skladištenje

\begin{abstract}
On the example of the organization CARLSBERG SERBIA DOO, ČELAREVO, an analysis of the storage process was performed. By applying appropriate methods and techniques, the most significant shortcomings in the mentioned process have been identified and analyzed, and based on the obtained results of the analysis, improvement measures have been proposed.
\end{abstract}

Keywords: Logistics, warehousing

\section{UVOD}

Ovaj rad sadrži teorijske osnove tj uopštenu terminologiju i definicije logistike i skladišnog poslovanja, informacije o preduzeću u kojem se sprovodila analiza skladišnog poslovanja, opis metoda koje su se koristile $\mathrm{u}$ radu tj Ishikawa metoda, snimak stanja i prikaz problema-spisak uočenih nedostataka u skladištu kao i njihov opis za koje su dati predlozi rešenja primenom metode, vremenski okvir tj gantogram sprovođenja mera unapređenja i finansijska analiza troškova predloženih rešenja i ostvarenih efekata.

\subsection{Logistika}

Logistika prestavlja proces strateškog upravljanja nabavkom, kretanjem i skladištenjem materijala i gotove robe kroz organizaciju i njene marketinške kanale, na najekonomičniji, najefikasniji i najprofitabilniji način za organizaciju i kupca.

Logistika uključuje sve poslovne funkcije i discipline koje se bave koordinacijom svih kretanja materijala, proizvoda i robe $u$ fizičkom, informacijskom i organizacijskom

\section{NAPOMENA:}

Ovaj rad proistekao je iz master rada čiji mentor je bio dr Nebojša Brkljač, docent. pogledu. Sastav logistike je skup elemenata tehničke, tehnološke, organizacijske, ekonomske i pravne oblasti radi optimizacije tokova materijala, roba, informacija, energije i ljudi na određenom području sa ciljem ostvarenja najvećih ekonomskih efekata [1].

Kontrola troškova je veoma važan segment poslovnog upravljanja, pa zato treba voditi računa i o logističkim troškovima. U zadnje dve decenije mnoga preduzeća ulažu velike napore da ih redukuju, povećavajući efikasnost logističkog upravljanja. Efikasan sistem planiranja, upravljanja i kontrole logističkog sistema je bitan preduslov, koji opredeljuje ne samo racionalnost već i konkurentnost i profitabilnost preduzeća u savremenim uslovima. Držanje logističkih troškova pod kontrolom pruža velike mogućnosti za uštede u poslovanju preduzeća, tj. u ukupnim troškovima. Sniženjem logističkih troškova osvaja se konkurentska prednost na tržištu [2].

\subsection{Skladišno poslovanje}

Skladišno poslovanje podrazumeva skup poslova koji se odnose na prihvatanje, čuvanje i izdavanje nabavljene (proizvedene) robe.

Skladište u širem smislu znači prostor izgrađen u celini, delimično izgrađen ili neizgrađen, ograničen ili ne ograničen, pokriven ili nepokriven, koji se upotrebljava za smeštaj robnih fondova preduzeća. Skladište u užem smislu podrazumeva samo onaj ograđen i pokriven prostor sa inventarom za manipulaciju, koji služi isključivo u svrhu uskladištenja i čuvanja robe od svih uticaja koji bi mogli dovesti do gubitaka na njoj. Skladište je posebno opremljena prostorija u kojoj se obavlja prijem, smeštaj, čuvanje, pakovanje, uzorkovanje, klasiranje, sortiranje, obeležavanje, utvrđivanje kvaliteta i izdavanje sirovina, poluproizvoda, gotovih proizvoda, ambalaže, sitnog inventara, kao i priprema ovih dobara za otpremu u proizvodne pogone, prodavnice ili kupcima [3].

\section{O PREDUZEĆU CARLSBERG SRBIJA}

DOO

Naziv preduzeća: CARLSBERG SRBIJA D.O.O., ČELAREVO

Datum osnivanja: 31.12.1998.

Adresa: Bačka Palanka-Čelarevo, Proleterska 17

Delatnost: Proizvodnja piva

Broj zaposlenih u Carlsberg Srbiji: oko 500 
Proizvodi Carlsberg pivare su Lav, Lav Premium, Twist (breskva, jagoda, limun), Tuborg, Carlsberg, Merak, Somersby, Budweiser, Erdinger, Guinness, San Miguel fresca, Grimbergen, Holsten, Zrenjaninsko, Kronenbourg 1664 Blanc [4].

\section{METODOLOGIJA RADA}

U daljem radu je korišćena metoda Ishikawa tj dijagram uzrok-posledica kako se još naziva metoda riblja kost, za otkrivanje uzroka problema/posledice. Ova metoda pomaže u boljem sagledavanju uzročno-posledičnih veza, analizi kao i definisanju rešenja za dati problem. Takođe, nakon predloga mera unapređenja je dat gantogram, kako bi se video vremenski okvir ostvarenja mera unapređenja tj aktivnosti.

\subsection{Ishikawa metoda}

Ishikawa dijagram je alat koji pomaže u identifikaciji, razvrstavanju i prikazivanju mogućih uzroka određenog problema, karakteristike kvaliteta i aspekata. Dijagram grafički prikazuje relacije između određene posledice i svih faktora koji na nju utiču. Ovaj dijagram je izumeo Kaoro Ishikawa $i$ često se zbog izgleda još zove i dijagram riblje kosti.

Više potencijalnih uzroka se grupiše u glavne kategorije i podkategorije, tako da njihov vizuelni prikaz podseća na riblju kost [5].

\subsection{Gantogram}

Gantogrami omogućavaju grafičko i vremensko planiranje odvijanja određenih poslova, odnosno grafički prikaz odvijanja određenih zadataka u vremenu.

Gantogrami se veoma uspešno koriste za globalno planiranje realizacije projekta, ali znatno više kod operativnog planiranja i praćenja realizacije dela ili faze projekta. Gantogram se formira tako što se na horizontalnoj osi predstavlja vreme $\mathrm{u}$ određenim vremenskim jedinicama, a na vertikalnoj osi predstavljaju se zadaci ili aktivnosti [6].

\section{SNIMAK STANJA I PRIKAZ PROBLEMA U MAGACINU PIVA}

Nakon snimka stanja uočeni su sledeći uzroci problema neefikasnosti procesa skladištenja u organizaciji:

1. nedovoljno iskorišćen prostor u delu sa rafovima

2. stavka ,čišćenje, iz $5 \mathrm{~S}$ metode se ne poštuje (podloške na podu, prašina, celofani i mala količina stakla)

3. izbledeli i oguljeni put kretanja u magacinu

4. nedovoljno označeni rafovi i zone sa proizvodima

5. neodgovornost radnika po pitanju nošenja zaštitne opreme

6. mali broj radnika u sred sezone kada je velika potražnja

7. veliki obim posla manuelnim radnicima

8. nedovoljno mesta za skladištenje u letnjoj sezoni

9. gubitak vremena u organizovanju mix paleta različitih proizvoda za maloprodajne klijente

10. neoznačen prostor za proizvode kojih je ostalo u malim količinama.
11. nepoklapanje stanja u programu i fizičkog stanja zaliha u magacinu

12. skidanje etiketa sa flaša zbog kondenzacije

13. manjak motivacije radnika usled velikog obima posla

14. kod loših procena potreba na tržištu ističu rokovi piva i gubi se vreme pri istakanju istog

\section{ANALIZA PROBLEMA I PREDLOG MERA UNAPREĐENJA}

\subsection{Analiza problema primenom dijagrama uzrok-} posledica

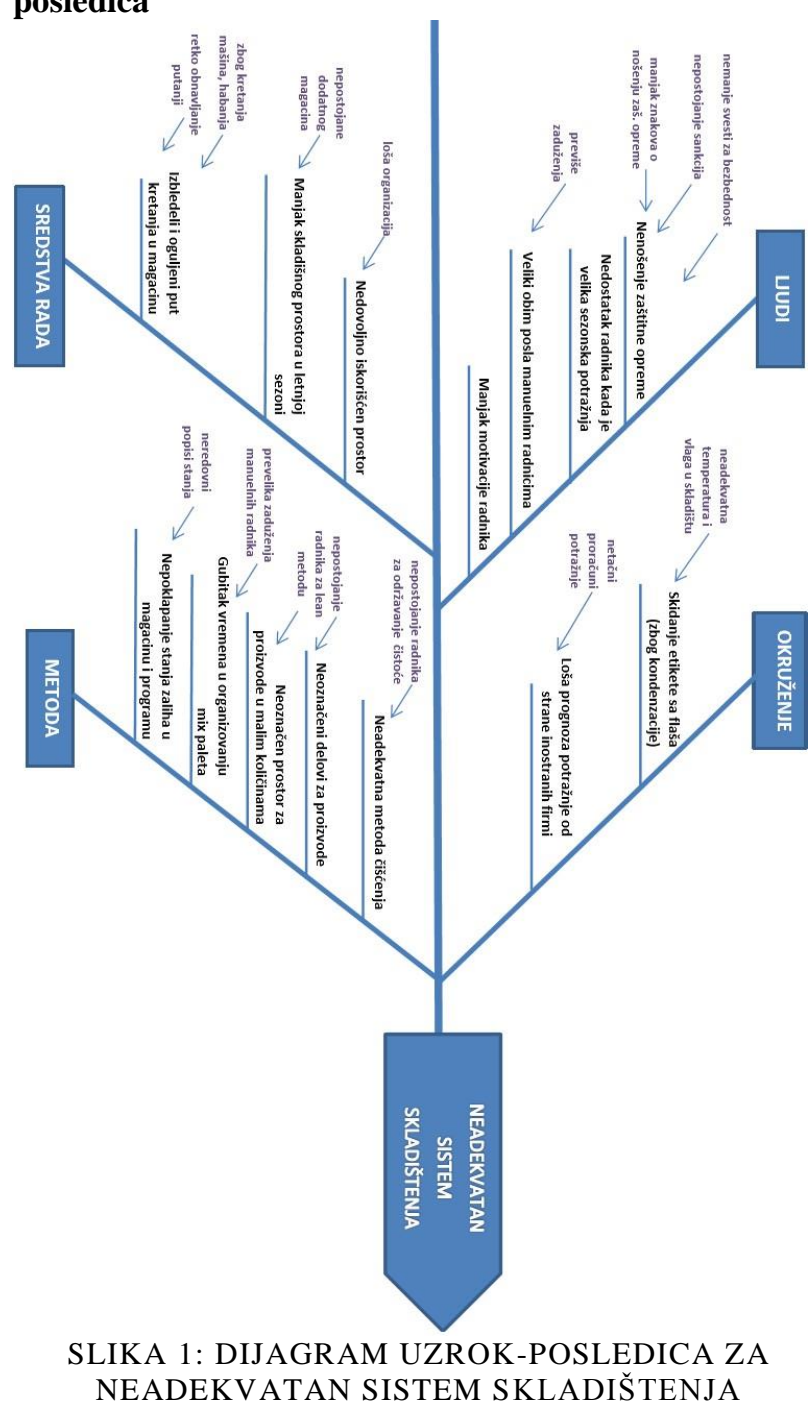

\subsection{Mere unapređenja}

Nakon sagledavanja dijagrama uzrok-posledica, dati su predlozi rešenja uzroka tj problema.

$\checkmark$ Predlog rešenja problema nenošenja zaštitne opreme:

Po pitanju neodgovornosti radnika oko nošenja zaštitne opreme potrebno je povećati safety walk (sigurnosna šetnja je kada linijski rukovodilac ili nadzor nadgleda rad koji se odvija, pregleda radno mesto i razgovara sa osobljem o bezbednosnim performansama na osnovu njihovih zapažanja) sa 20 na 40 puta godišnje, dakle jednom nedeljno $\mathrm{i}$ tokom te vizite beležiti near miss (mogućnosti povrede na radu) sa opisom koja se mera ne poštuje i zašto. Safety walk bi obavljalo lice iz ljudskih resursa sa šefom magacina. 
Ako radnik dobije 2 near miss-a treba da sledi usmena opomena od strane osoblja koje vrši kontrolu.

U slučaju da ostvare 3 near miss-a, treba da sledi opomena od strane ljudskih resursa i opomena o prekidu ugovora o radu u slučaju da se još jednom ne poštuje mera.

Takođe je neophodno postaviti još vizuelnih znakova o obaveznom nošenju zaštitne opreme na svakoj raskrsnici i svakom ulazu u visini očiju kako bi bili uočljiviji.

$\checkmark$ Predlog rešenja problema nedostatka radnika kada je velika sezonska potražnja:

Kada je centar sezone i velika potražnja treba zaposliti sezonske radnike, npr. studente preko zadruge koji će obavljati posao sve dok je potrebno. Takođe, oni moraju proći kratku obuku o zaštiti na radu pre početka rada. Oni bi radili od juna do avgusta i poželjno je zaposliti za svaku smenu po 3 radnika.

$\checkmark$ Predlog rešenja problema prevelikog obima posla manuelnim radnicima:

Zapošljavanjem radnika za održavanje čistoće se smanjuje obim posla manuelnim radnicima. Među njima je preporučljivo podeliti zaduženja da jedan manuelni radnik bude zadužen za prepakivanje robe u toku smene, drugi za stikerisanje, treći za sklapanje mix paleta i ručno manitupisanje robom.

Ako jedan radnik ne postiže sam neki od poslova, sledeći koji je završio sa svojim zaduženjima treba da pomogne. Npr. kada radnik završi sa prepakivanjem robe, odlazi kod radnika koji manipuliše robom i pravi mix paleta da zajedno rade, kako ne bi bilo praznog hoda.

$\checkmark \quad$ Predlog rešenja manjka motivacije radnika:

Da bi se podigao nivo motivacije radnika, na osnovu truda, učinka i posvećenosti radnika koje meri sektor ljudskih resursa, uvesti nagrade za radnike meseca u vidu bonusa na platu. Poželjno je organizovati periodične team buildinge, npr. 4 puta godišnje, kako bi se podigao nivo timskog učešća i motivacija.

$\checkmark$ Predlog rešenja skidanja etiketa sa flaša zbog kondenzacije:

Problem razlike $\mathrm{u}$ temperaturama $\mathrm{u}$ proizvodnji $\mathrm{i}$ magacinu koji dovodi do kondenzacije i vlaženja flaša piva, koji ima posledicu skidanja etiketa sa flaša je moguće rešiti postavkom termometra unutar magacina koji će tačno meriti temperaturu i vlažnost. Radnici u svakoj smeni trebaju kontrolisati i unositi u tabelu iznose temperature, kako bi mogli pratiti stanje. Takođe je neophodno postaviti klime koje regulišu temperaturu i vlažnost vazduha i ventilaciju, kako bi se kondenzacija sprečila.

$\checkmark \quad$ Predlog rešenja za loše proračune potražnje od strane inostranih firmi:

Da ne bi došlo do loše proračunate potražnje od strane inostranih firmi, neophodno je angažovati radnike koji će što približnije odrediti odnose potrebe i potražnje na tržištu za datim proizvodima. Dakle, potrebno je zaposliti 2 radnika u sektoru marketinga, koji će se baviti proračunom potražnje $\mathrm{i}$ istraživanjem tržišta.

$\checkmark$ Predlog rešenja za nedovoljno iskorišćen prostor u magacinu:

Dodati u delu magacina sa rafovima još jedan red rafova u sredini kako bi bila bolja iskorišćenost prostora. Nakon premeravanja ima dovoljno prostora za prolazak viljuškarista i više prostora za skladištenje robe. $\checkmark \quad$ Predlog rešenja manjka skladišnog prostora $u$ letnjoj sezoni:

Svake letnje sezone se javlja potreba za dodatnim skladištem. Predlog rešenja bi bio da se postavi montažni magacin od 500 kvadrata u dvorištu kompanije, jer tamo ima dovoljno prostora. To bi olakšalo dosta manipulaciju robom i organizovanje isporuka.

$\checkmark \quad$ Predlog rešenja izbledeli i oguljeni put kretanja u magacinu:

S obzirom da se putanja u magacinu često izguli i izbledi, zahteva se periodično obnavljanje putanja i obeležavanje. To radi eksterna firma zadužena za iscrtavanje bezbednosnih putanja jednom ili dva puta godišnje. Kada putanja izbledi potrebno je nabaviti trake za pod $\mathrm{u}$ žutoj boji za prvu pomoć dok se putanje ne obnove od strane stručne firme. Trake bi lepili radnici održavanja čistoće po već postojećim trakama koje su izbledele, nakon što prethodno pripreme podlogu (očiste je od prašine i otpada), radi boljeg prijanjanja.

$\checkmark \quad$ Predlog rešenja za neadekvatnu metodu čišćenja: Da bi se rešilo čišćenje neophodno je angažovati po jednog radnika za svaku smenu, koji će biti zadužen za održavanje čistoće magacina. Njegova zaduženja bi bila isključivo skupljanje otpada koji se našao u magacinu tokom rada (podloške, celofani, staklo), čišćenje podova mašinom za čišćenje koja već postoji u okviru fabrike. Angažovanjem radnika za održavanje čistoće se smanjuje obim posla manuelnim radnicima, koji su već prebukirani sa zaduženjima.

$\checkmark$ Predlog rešenja za neoznačene delove sa proizvodima:

U okviru sektora za logistiku, zaposliti 2 radnika koji će biti „method and time“ specijalisti. Oni će organizovati gde koji proizvod treba da stoji, izrađivati layout $\mathrm{u}$ wordu ili excelu sa njihovim pozicijama i na osnovu toga obeležavati svaki deo magacina, zone, rafove. U svakoj zoni će pisati koji se proizvod tu nalazi kao i njihova boja radi lakše prepoznatljivosti. Layout za svaku zonu je neophodno odštampati, plastificirati i okačiti na vidno mesto. Kod rafova na početku u visini očiju gde stoji i znak za obavezno korišćenje zaštitne opreme. Svaki red rafova mora imati naziv proizvoda sa njihovom karakterističnom bojom.

$\checkmark$ Predlog rešenja za neoznačen prostor za proizvode u malim količinama:

Odrediti jednu zonu u drugom delu magacina i označiti je za proizvode kojih je ostalo u malim količinama. Zonu na osnovu vizuelne analize trebaju odrediti „method and time" specijalisti koje je neophodno zaposliti.

$\checkmark$ Predlog rešenja gubitak vremena u organizovanju mix paleta:

Mix paleta bi rešavao manuelni radnik koji bi bio zadužen samo za sklapanje mix paleta, kako bi stigao da postigne zadati cilj. On bi bio raspoređen samo za ovu vrstu posla $i$ time bi imao više vremena.

$\checkmark$ Predlog rešenja nepoklapanja stanja zaliha u magacinu i programu:

Da ne bi došlo do nepoklapanja stanja zaliha u programu i fizičkog stanja zaliha u magacinu, potrebno je da magacioner vrši popis stavki nakon svake smene (3 smene) gde se poredi fizičko stanje u magacinu po pitanju zaliha $\mathrm{i}$ stanje $\mathrm{u}$ programu SAP. Ukoliko ima nepravilnosti, greška se odmah otklanja, tako da se stanje 
u programu i u magacinu nakon svake smene u potpunosti poklapa.

\section{GANTOGRAM SPROVOĐENJA MERA UNAPREĐENJA}

Gantogram je prikazan na slici 2.

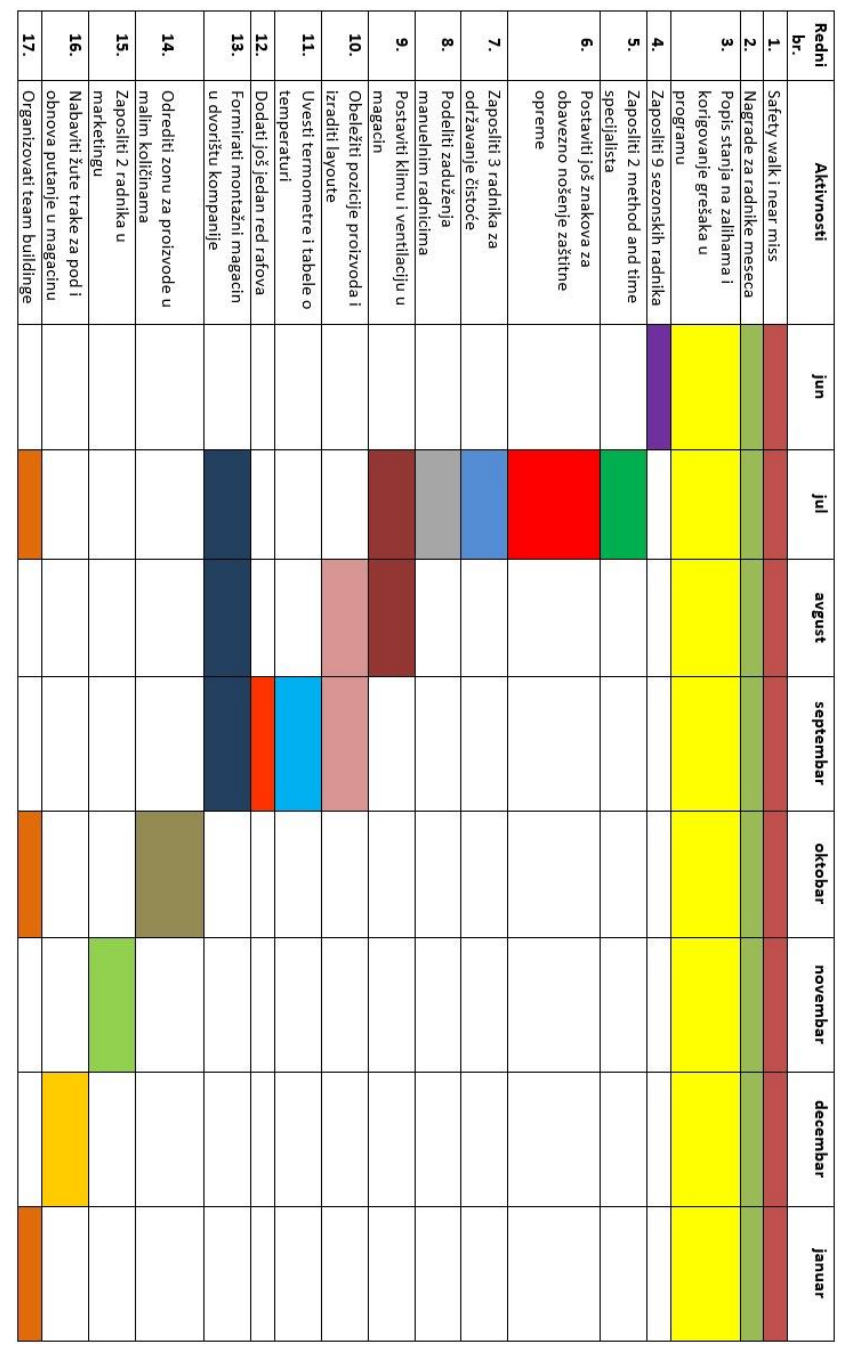

SLIKA 2:GANTOGRAM SPROVOĐENJA MERA

\section{FINANSIJSKA ANALIZA TROŠKOVA PREDLOŽENIH REŠENJA I OSTVARENIH EFEKATA}

Analiza je prikazana u Tabeli 1 .

\section{ZAKLJUČAK}

Ovim doprinosom, odnosno unapređenjem skladištenja, odvijanje poslova u skladištu i distribuciji robe trebalo bi doprineti bolje, brže, produktivnije procese rada preduzeća.

Tako bi firma Carlsberg Čelarevo, nakon nekog vremena mogla vratiti investicije uložene $u$ unapređenje, te ostvariti dobit i biti konkurentnija na tržištu, ali i daljim napredovanjem postati lider na tržištu.

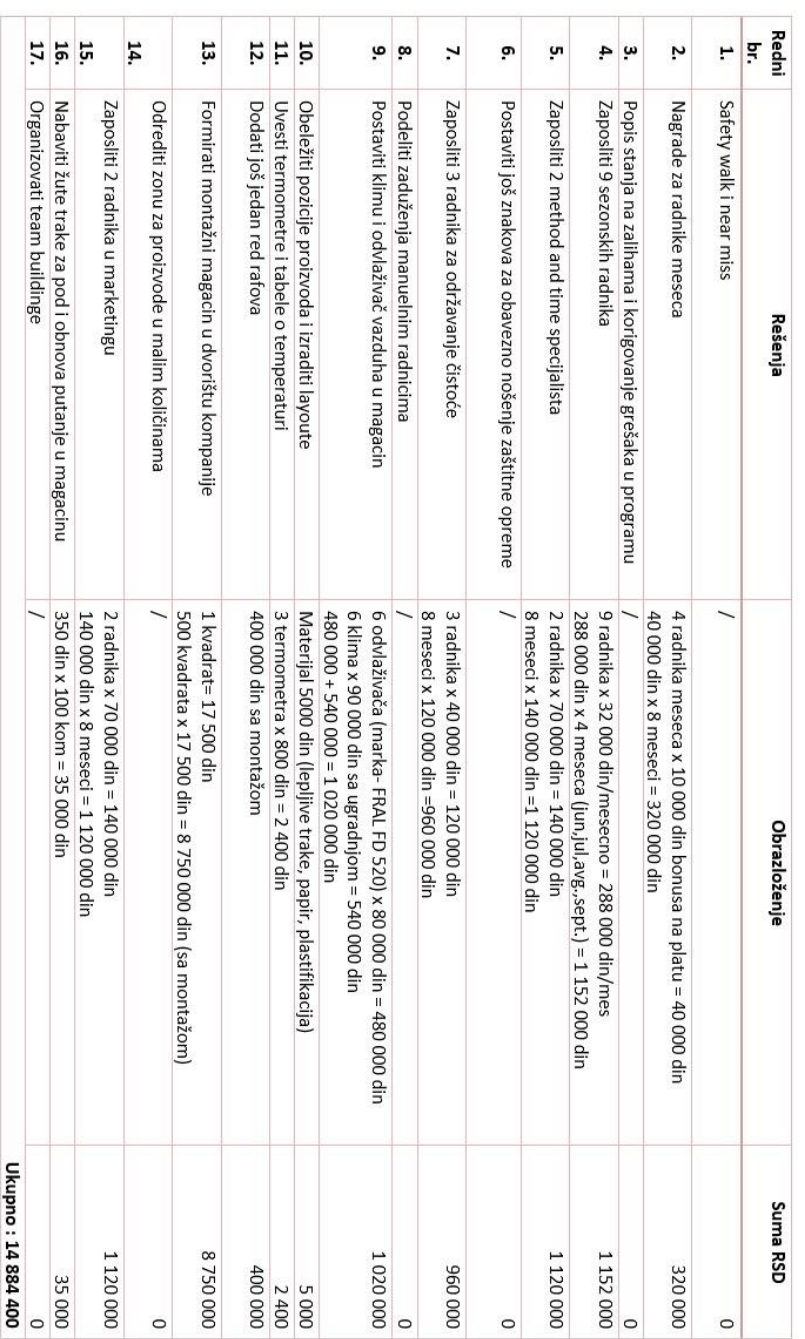

TABELA 1: FINANSIJSKA ANALIZA SPROVOĐENJA MERA UNAPREĐENJA

\section{LITERATURA}

[1] https://bestlogistika.blogspot.com/2008/07/definicijelogistike.html

[2] https://www.industrija.rs/vesti/clanak/logistikaneizbezna-karika-u-poslovanju

[3] http://www.vps.ns.ac.rs/Materijal/mat10952.pdf

[4] https://carlsbergsrbija.rs/

[5] http://www.masfak.ni.ac.rs/images/upload/Upis/MAS prirpemna n/uvod u_m _pripremna/5._Alati_kvaliteta-Ishikawa_metoda.pdf

[6] http://men.fon.bg.ac.rs/wpcontent/uploads/2019/10/Strukturni-dijagramiGantogram-Planiranje-Compatibility-Mode.pdf

\section{Kratka biografija:}

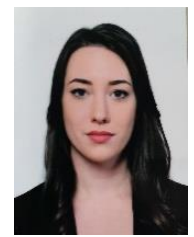

Lana Mitić rođena je u Novom Sadu 1995. god. Diplomirala na Fakultetu tehničkih nauka iz oblasti Inženjerski menadžment - logistika 2019. godine. 